\title{
Quantum Chemical Investigation on the Antioxidant Activity of Neutral and Anionic Forms of Juglone: Metal Chelation and Its Effect on Radical Scavenging Activity
}

\author{
Aymard Didier Fouegue Tamafo, ${ }^{1}$ Julius Numbonui Ghogomu, ${ }^{1}$ \\ Nyiang Kennet Nkungli, ${ }^{1}$ Désiré Bikélé Mama, ${ }^{2}$ and Elie Younang ${ }^{3}$ \\ ${ }^{1}$ Department of Chemistry, Faculty of Science, University of Dschang, P.O. Box 67, Dschang, Cameroon \\ ${ }^{2}$ Department of Chemistry, Faculty of Science, University of Douala, P.O. Box 24157, Douala, Cameroon \\ ${ }^{3}$ Department of Inorganic Chemistry, Faculty of Science, University of Yaoundé I, P.O. Box 812, Yaoundé, Cameroon
}

Correspondence should be addressed to Julius Numbonui Ghogomu; ghogsjuju@hotmail.com

Received 5 March 2017; Accepted 3 May 2017; Published 31 May 2017

Academic Editor: Zhongfang Chen

Copyright (C) 2017 Aymard Didier Fouegue Tamafo et al. This is an open access article distributed under the Creative Commons Attribution License, which permits unrestricted use, distribution, and reproduction in any medium, provided the original work is properly cited.

\begin{abstract}
The chelation ability of divalent $\mathrm{Mg}, \mathrm{Ca}, \mathrm{Fe}, \mathrm{Co}, \mathrm{Ni}, \mathrm{Cu}, \mathrm{Zn}$, and monovalent $\mathrm{Cu}$ ions by neutral and anionic forms of juglone has been investigated at DFT/B3LYP/6-31+G(d,p) level of theory in gas and aqueous phases. It is noteworthy that only the $1: 1$ stoichiometry was considered herein. The effects of these metals on the radical scavenging activity of neutral juglone were evaluated via the usual descriptors of hydrogen atom transfer. According to our results, metal chelation by the two forms of juglone was spontaneous and exothermic in both media. Based on the binding energies, $\mathrm{Cu}(\mathrm{II})$ ion showed the highest affinity for the ligands. QTAIM analyses identified the metal-ligand bonds as intermediate type interactions in all the chelates, except those of Ca and Mg. It was also found that the chelates were better radical scavengers than the ligands. In the gas phase, the scavenging activity of the compounds was found to be governed by direct hydrogen atom transfer, the $\mathrm{Co}$ (II) chelate being the most reactive. In the aqueous phase also, the sequential proton loss electron transfer was preferred by all the molecules, while the $\mathrm{Cu}(\mathrm{II})$ chelates were the most reactive.
\end{abstract}

\section{Introduction}

In living organisms, transition metal ions $\left(\mathrm{M}^{n+}\right)$ in their lower oxidation states ( $n=1$ or 2 ) can catalyze oxidative reactions by reducing their activation energy. By doing so, this may lead to the formation of very dangerous reactive oxygen species on the one hand, most common of which are the hydroxyl radicals $\left(\mathrm{HO}^{*}\right)$, reactive nitrogen species [1-5], and oxidized metal ions $\mathrm{M}^{(n+1)+}(1)$, via Fenton reactions on the other $[2,6]$. Direct consequences of this are diseases such as cancer, cataract, Alzheimer and Parkinson diseases, accelerated ageing, arthritis, and compromised immune systems:

$$
\mathrm{M}^{n+}+\mathrm{HOOH} \longrightarrow \mathrm{M}^{(n+1)+}+\mathrm{HO}^{-}+\mathrm{HO}^{\bullet}
$$

In the presence of the superoxide radical $\left(\mathrm{O}_{2}{ }^{-*}\right)$ or some other antioxidant molecules like ascorbic acid $\left(\mathrm{AH}_{2}\right)$ or polyphenols $(\mathrm{PhOH})((2)$ and (3)), the oxidized state of the metal ions $\mathrm{M}^{(n+1)+}$ is reduced to $\mathrm{M}^{n+}$ [3], which in turn undergoes another Fenton reaction.

$$
\begin{gathered}
\mathrm{M}^{(n+1)+}+2 \mathrm{AH}_{2} \longrightarrow \mathrm{M}^{n+}+2 \mathrm{AH}^{\bullet}+2 \mathrm{H}^{+} \\
\mathrm{M}^{(n+1)+}+\mathrm{PhOH} \longrightarrow \mathrm{M}^{n+}+\mathrm{PhO}^{\bullet}+\mathrm{H}^{+}
\end{gathered}
$$

Metal-chelating compounds encompassing antioxidants that are capable of altering their redox potentials, that is, capable of removing metals from their surrounding environments, are very important in foods processing, beverages, cosmetics, metal corrosion, pharmaceutical formulations, and living organisms [3, 7-11]. From the foregoing, a high affinity for the targeted metal ions by the antioxidant, which results in their greater capability of scavenging the free active 
metal ions, is one of the key features of a good chelating agent [12]. Indeed, natural polyphenols can chelate metal ions in order to prevent the generation of reactive hydroxyl radicals [13-15]. Typically, these polyphenols bind to transition metal ions via their hydroxyl, carbonyl, and carboxyl groups. This binding process occurs through an acid-base reaction in which the metal ion acts as the Lewis acid and the polyphenol functions as the Lewis base. The above-mentioned solutions toward mitigating the excesses of transition metal ions in living organisms have been subject to many studies [912].

In a previous paper, we evaluated the $\mathrm{Fe}^{2+}$ ion chelating ability of neutral juglone (5-hydroxy-1,4-naphthoquinone) and two of its derivatives by means of the density functional theory (DFT) [16]. In this paper, the effect of the Fe(II) ion chelation on the antioxidant activity of juglone and its derivatives was evaluated. However, apart from $\mathrm{Fe}^{2+}$ ion, food and cosmetic ingredients, lipids, polymer materials, and living organisms also contain many other transition as well as alkali-earth metal ions. Unfortunately, some of these transition metal ions can catalyze the formation of free radicals. Against this backdrop, the present article aims at identifying the metal ions in living organisms having the highest affinity toward neutral and deprotonated juglone. Moreover, the effects of these metals on the radical scavenging activity of juglone in gas and aqueous media have been investigated herein. To attain this objective, the ions $\mathrm{Fe}^{2+}$, $\mathrm{Co}^{2+}, \mathrm{Ni}^{2+}, \mathrm{Cu}^{2+}, \mathrm{Zn}^{2+}, \mathrm{Ca}^{2+}$, and $\mathrm{Mg}^{2+}$ as well as $\mathrm{Cu}^{+}$ have been chosen because they are of paramount importance in bioinorganic chemistry and also for their abundance in enzymes. Additionally, these ions are highly involved in the strengthening of living organisms. To the best of our knowledge, the present work is the first attempt of utilizing quantum chemical tools in studying the metal selectivity of juglone toward the above-mentioned metals, as well as the antiradical properties of the resulting chelates.

To achieve these objectives, the thermodynamic parameters (reaction enthalpies and free energies of formation) as well as interaction energies have been employed to study the stability of the chelates. Bader's Quantum Theory of Atom in Molecules (QTAIM) and the Natural Bond Analysis (NBO) were used to study the metal-ligand interactions. The usual thermodynamic descriptors of antioxidant activity (AOA) were used to evaluate the effect of the metal ions on the radical scavenging activity of neutral juglone. These descriptors are [17] as follows:

(i) the bond dissociation enthalpy (BDE) characterizing the direct hydrogen atom transfer from the antioxidant $(\mathrm{MJ}-\mathrm{OH})$ to a free radical as

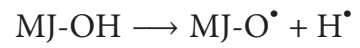

(ii) the ionization potential (IP) and proton dissociation enthalpy (PDE), describing the electron transferproton transfer mechanism (ET-PT) as

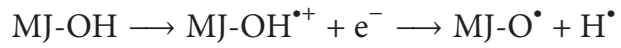

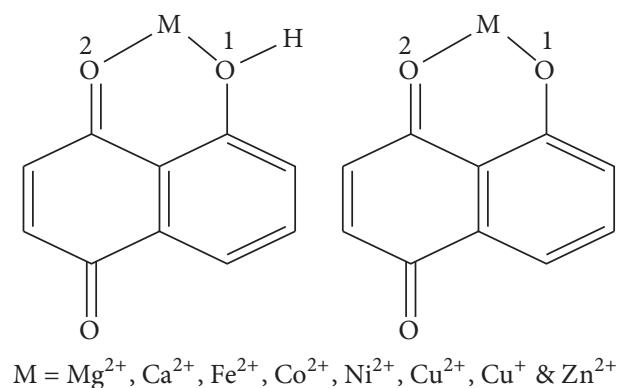

FIgURE 1: Structures of the studied chelates.

(iii) the proton affinity and the electron transfer enthalpy (PA and ETE, (6)) describing the sequential proton transfer electron transfer (SPT-ET) mechanism:

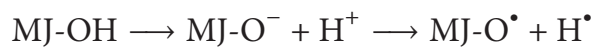

\section{Theoretical Background and Computational Details}

All electronic structure calculations have been performed at DFT/B3LYP/6-31+G(d,p) level [18-24] in the gas and the aqueous phases, using the Gaussian 09 package [25]. No symmetry constraints were used during geometry optimizations. With the aim of determining the nature of all the stationary points, frequency calculations were performed on all the optimized geometries at the same level of theory. The DFT/B3LYP method was used because it is frequently employed for the studies on metalation of natural antioxidant [9-11, 26]. The calculations on closed shell systems were performed by the means of the Restricted Kohn-Sham formalism whereas the Unrestricted Kohn-Sham approach was used for open shell systems [23, 27]. The IEF-PCM (Integral Equation Formulation-Polarizable Continuum Model) solvation model $[28,29]$ has been used in this work to predict the effect of water on the studied properties.

The enthalpies and free energies of formation for the different chelates (Figure 1) as well as their interaction energies were calculated via (7). In this equation, $Q$ stands for the enthalpy, the free energy or the thermal energy of the chelates, the ligands, and the central metal ions. Here, the ligands are both the neutral and deprotonated forms of juglone.

$$
\Delta Q=Q_{\mathrm{L}-\mathrm{M}}-\mathrm{Q}_{\mathrm{L}}-\mathrm{Q}_{\mathrm{M}^{n+}}
$$

The Natural Population Analysis (NPA) charge [30] on the central metal ions has been calculated and used to evaluate the degree of reduction of these metals after their chelation by the ligands. The nature of all metal-ligand bonds was studied via the Quantum Theory of Atom in Molecules (QTAIM) proposed by Bader [31], as implemented in Multiwfn [32].

The effects of all eight metal ions studied on the antioxidant activity of juglone have been investigated using the 
TABLE 1: Gas phase energies (Hartree) of the Fe(II), $\mathrm{Co}(\mathrm{II})$, and $\mathrm{Ni}(\mathrm{II})$ chelates related to their multiplicities calculated at B3LYP/6-31+G(d,p) level of theory.

\begin{tabular}{lcccc}
\hline & & Juglone & \multicolumn{2}{c}{ Deprotonated juglone } \\
& Low multiplicity & High multiplicity & Low multiplicity & High multiplicity \\
\hline $\mathrm{Fe}(\mathrm{II})$ & -1873.11248 & -1873.19968 & -1872.96805 & -1873.04352 \\
$\mathrm{Co}(\mathrm{II})$ & -1992.19774 & -1992.21763 & -1992.17881 & -1992.06371 \\
$\mathrm{Ni}(\mathrm{II})$ & -2117.71185 & -2117.74145 & -2117.57340 & -2117.59036 \\
\hline
\end{tabular}

TABLE 2: Gas and water phases values of the O-metal and O-H bond lengths (angstrom) of the chelates obtained from the optimized geometries at DFT/B3LYP/6-31+(d,p) level.

\begin{tabular}{|c|c|c|c|c|c|c|c|c|c|c|}
\hline & \multicolumn{6}{|c|}{ Juglone } & \multicolumn{4}{|c|}{ Deprotonated juglone } \\
\hline & \multicolumn{3}{|c|}{ Gas } & \multicolumn{3}{|c|}{ Water } & \multicolumn{2}{|c|}{ Gas } & \multicolumn{2}{|c|}{ Water } \\
\hline & $\mathrm{O}_{1}-\mathrm{M}$ & $\mathrm{O}_{2}-\mathrm{M}$ & $\mathrm{O}-\mathrm{H}$ & $\mathrm{O}_{1}-\mathrm{M}$ & $\mathrm{O}_{2}-\mathrm{M}$ & $\mathrm{O}-\mathrm{H}$ & $\mathrm{O}_{1}-\mathrm{M}$ & $\mathrm{O}_{2}-\mathrm{M}$ & $\mathrm{O}_{1}-\mathrm{M}$ & $\mathrm{O}_{2}-\mathrm{M}$ \\
\hline $\mathrm{J}-\mathrm{Mg}$ & 1.967 & 1.854 & 0.975 & 2.101 & 1.976 & 0.972 & 1.839 & 1.874 & 1.951 & 1.985 \\
\hline $\mathrm{J}-\mathrm{Ca}$ & 2.386 & 2.180 & 0.973 & 2.664 & 2.431 & 0.971 & 2.152 & 2.205 & 2.331 & 2.394 \\
\hline $\mathrm{J}-\mathrm{Fe}$ & 1.973 & 1.867 & 0.977 & 2.136 & 1.952 & 0.973 & 1.799 & 1.916 & 1.901 & 1.971 \\
\hline $\mathrm{J}-\mathrm{Co}$ & 1.934 & 1.891 & 0.979 & 2.032 & 1.936 & 0.973 & 1.790 & 1.912 & 1.868 & 1.976 \\
\hline $\mathrm{J}-\mathrm{Ni}$ & 1.932 & 1.845 & 0.979 & 2.013 & 1.909 & 0.973 & 1.781 & 1.873 & 1.854 & 1.915 \\
\hline $\mathrm{J}-\mathrm{Cu}$ & 2.080 & 1.910 & 0.974 & 1.936 & 1.834 & 0.976 & 1.925 & 1.950 & 1.816 & 1.846 \\
\hline $\mathrm{J}-\mathrm{Cu}(\mathrm{I})$ & 2.087 & 1.918 & 0.970 & 2.123 & 1.942 & 0.971 & 1.888 & 1.914 & 1.921 & 1.939 \\
\hline $\mathrm{J}-\mathrm{Zn}$ & 1.926 & 1.832 & 0.976 & 2.106 & 1.962 & 0.972 & 1.812 & 1.847 & 1.905 & 1.945 \\
\hline
\end{tabular}

following equations, which are based on the hydrogen atom transfer mechanisms ((4)-(6)):

$$
\begin{aligned}
\mathrm{BDE} & =\mathrm{H}_{\mathrm{MJ}-\mathrm{O}}+\mathrm{H}_{\mathrm{H}^{\bullet}-\mathrm{H}_{\mathrm{MJ}-\mathrm{OH}}} \\
\mathrm{IP} & =\mathrm{H}_{\mathrm{MJ}-\mathrm{OH}^{+}}+\mathrm{H}_{e^{-}}-\mathrm{H}_{\mathrm{MJ}-\mathrm{OH}} \\
\mathrm{PDE} & =\mathrm{H}_{\mathrm{MJ}-\mathrm{O}^{\bullet}}+\mathrm{H}_{\mathrm{H}^{+}}-\mathrm{H}_{\mathrm{MJ}-\mathrm{OH}^{+}} \\
\mathrm{PA} & =\mathrm{H}_{\mathrm{MJ}-\mathrm{O}^{-}}+\mathrm{H}_{\mathrm{H}^{+}-\mathrm{H}_{\mathrm{MJ}-\mathrm{OH}}} \\
\mathrm{ETE} & =\mathrm{H}_{\mathrm{MJ}-\mathrm{O}^{\bullet}}+\mathrm{H}_{e^{--}}-\mathrm{H}_{\mathrm{MJ}-\mathrm{O}^{-}}
\end{aligned}
$$

In these equations, $H$ stands for the enthalpy of formation of the species calculated at $298.15 \mathrm{~K}$ and $1 \mathrm{~atm}$. Aimed at studying the spontaneity of the AOA mechanisms, the free energies of these mechanisms have also been calculated by replacing $H$ with $G$, the free energy of formation.

\section{Results and Discussion}

3.1. Effect of Multiplicity. Since the multiplicities of the chelates and complexes are dependent on the strength of the ligands, the first section of the results is devoted to the study of the energies of the highest and lowest multiplicity states of iron, cobalt, and nickel chelates. These states are singlet and quintet, singlet and quartet, and singlet and triplet, respectively, for the iron, cobalt, and nickel chelates. This investigation was carried out in gas phase for juglone and deprotonated juglone chelates, and the states of multiplicity adopted have been used in the aqueous phase. The energies of the aforementioned multiplicity states are presented in Table 1 . In the case of the $\mathrm{Mg}(\mathrm{II}), \mathrm{Ca}(\mathrm{II}), \mathrm{Cu}(\mathrm{I})$, and $\mathrm{Cu}(\mathrm{II})$ as well as $\mathrm{Zn}$ (II) chelates, the effect of multiplicity has not been investigated because only one multiplicity state (doublet for $\mathrm{Cu}(\mathrm{II})$ and singlet for the rest of chelates) is adopted.

It is clear from Table 1 that, for all the chelates, the highest multiplicity state is the most stable (that with the lowest energy). Therefore, the quintet, quartet, and triplet states of $\mathrm{Fe}$ (II), $\mathrm{Co}(\mathrm{II})$, and $\mathrm{Ni}$ (II) chelates will be adopted throughout the rest of the work. The $\left\langle S^{2}\right\rangle$ values of the high multiplicity state for the $\mathrm{Fe}(\mathrm{II}), \mathrm{Co}(\mathrm{II})$, and $\mathrm{Ni}(\mathrm{II})$ chelates of juglone are, respectively, 6.00, 3.75, and 2.00. For the deprotonated juglone compounds, these $\left\langle S^{2}\right\rangle$ values are $6.00,3.75$, and 2.00, respectively, for the $\mathrm{Fe}(\mathrm{II}), \mathrm{Co}(\mathrm{II})$, and $\mathrm{Ni}$ (II) chelates. Interestingly, all of these values are equal to the $\left\langle S^{2}\right\rangle$ values of the pure quintet, quartet, and triplet wave functions, which are $6.00,3.75$, and 2.00 , respectively.

3.2. Geometric Parameters. The gas phase optimized geometries of all the chelates are presented in Figure 2. The values of the metal-ligand bond lengths as well as those of the $\mathrm{O}-\mathrm{H}$ bonds are reported in Table 2. The variation of these metal-ligand bond lengths has been plotted and presented in Figure 3. The labeling has been described in Figure 1.

It can be seen from Figure 3 that, in both gas and aqueous phases, the lengths of the $\mathrm{M}-\mathrm{O}_{1}$ bonds are longer than those of the $\mathrm{M}-\mathrm{O}_{2}$ bonds in juglone chelates. It is clearly evidenced from the figure that, apart from the $\mathrm{Cu}(\mathrm{II})$ chelate, the solvent environment increases the two $\mathrm{M}-\mathrm{O}$ bond lengths, which is apparently responsible for the interaction energy increment ongoing from the gas to the solvent phase. A similar observation is made in the case of the chelates of deprotonated juglone as depicted in Figure 3. However, in 

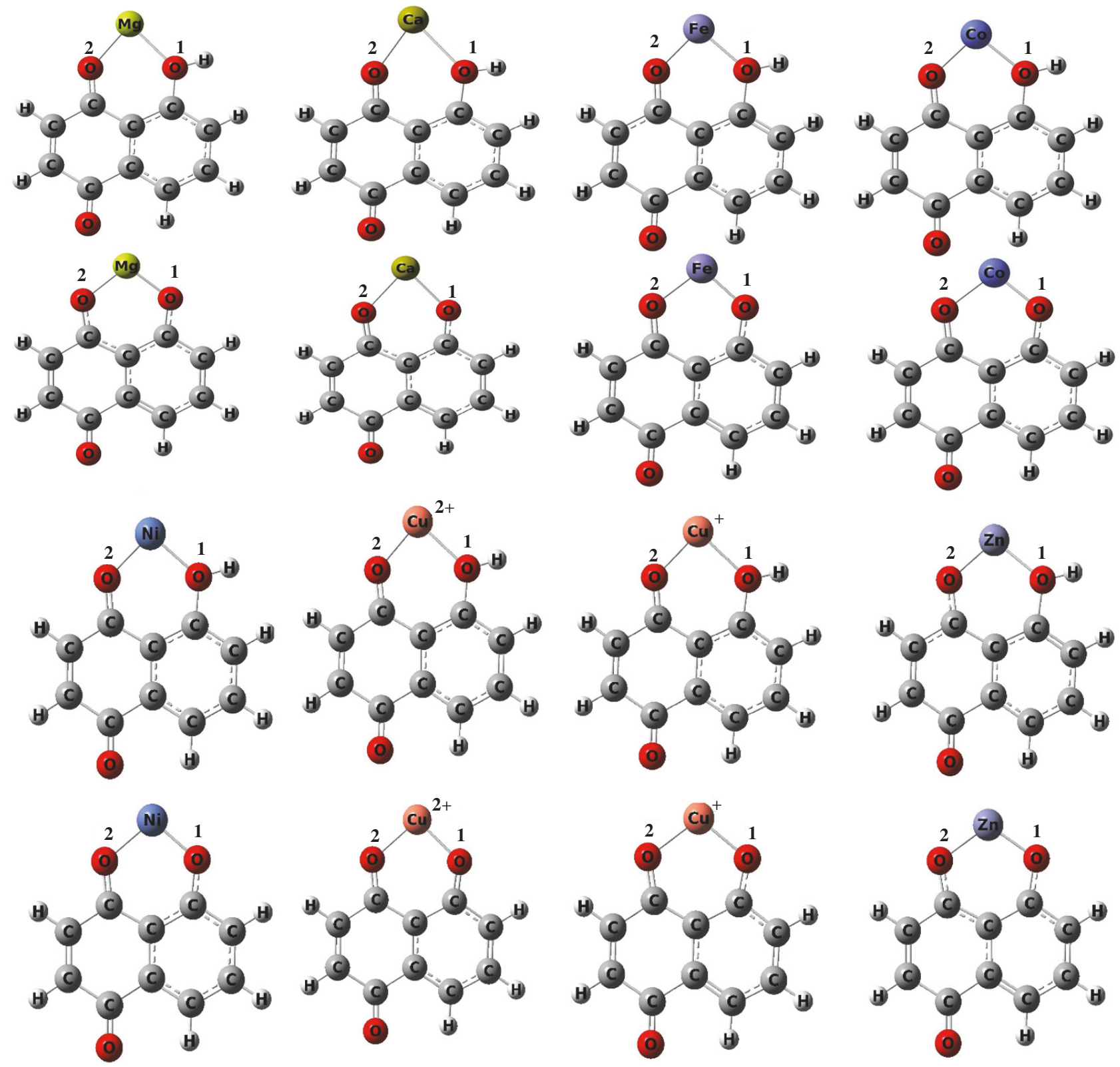

FIGURE 2: Gas phase optimized geometries of the chelates obtained at B3LYP/6-31+G(d,p) level of theory.

these compounds the $\mathrm{M}-\mathrm{O}_{1}$ bonds are shorter than the $\mathrm{M}-\mathrm{O}_{2}$ bonds owing to the negative charge carried by the $\mathrm{O}_{1}$ atom, which increases its basicity relative to that of $\mathrm{O}_{2}$. Because of this negative charge, the $\mathrm{M}-\mathrm{O}$ bond lengths are shorter in the chelates of anionic juglone than in those of neutral juglone.

The lengths of the $\mathrm{O}-\mathrm{H}$ bond in the chelates of the neutral form of juglone are presented in Table 2. In gas phase, the length of this bond lies within the range 0.970 to $0.979 \AA$, with the Co and Ni chelates having the highest values. Apart from the two $\mathrm{Cu}$ chelates, the presence of water leads to slight discrepancies in the $\mathrm{O}-\mathrm{H}$ bond lengths. In this solvent, the length of this bond lies within 0.971 and $0.976 \AA$, with the $\mathrm{Cu}$ (II) chelate having the highest values. Based on these results, the best antioxidants in gas phase are certainly the
$\mathrm{Ni}(\mathrm{II})$ and $\mathrm{Co}$ (II) chelates whereas the best antioxidant in aqueous phase is the $\mathrm{Cu}(\mathrm{II})$ chelate.

3.3. Chelation Ability. The chelating ability of both neutral and deprotonated juglone toward the $\mathrm{Mg}(\mathrm{II}), \mathrm{Ca}(\mathrm{II}), \mathrm{Fe}(\mathrm{II})$, $\mathrm{Co}(\mathrm{II}), \mathrm{Ni}(\mathrm{II}), \mathrm{Cu}(\mathrm{II}), \mathrm{Cu}(\mathrm{I})$, and $\mathrm{Zn}(\mathrm{II})$ ions has been evaluated through the enthalpies $(\Delta H)$ and free energies $(\Delta G)$ of formation of the chelates, as well as the complexation (binding) energies $(\Delta E)$ as summarized in (7). The values of these thermodynamic parameters calculated at $298.15 \mathrm{~K}$ and $1 \mathrm{~atm}$ are reported in Table 3 . It is obvious from the values in Table 3 that the formation of all the juglone chelates in gas phase is exothermic and exergonic, meaning that these reactions are thermodynamically feasible. The formation of 

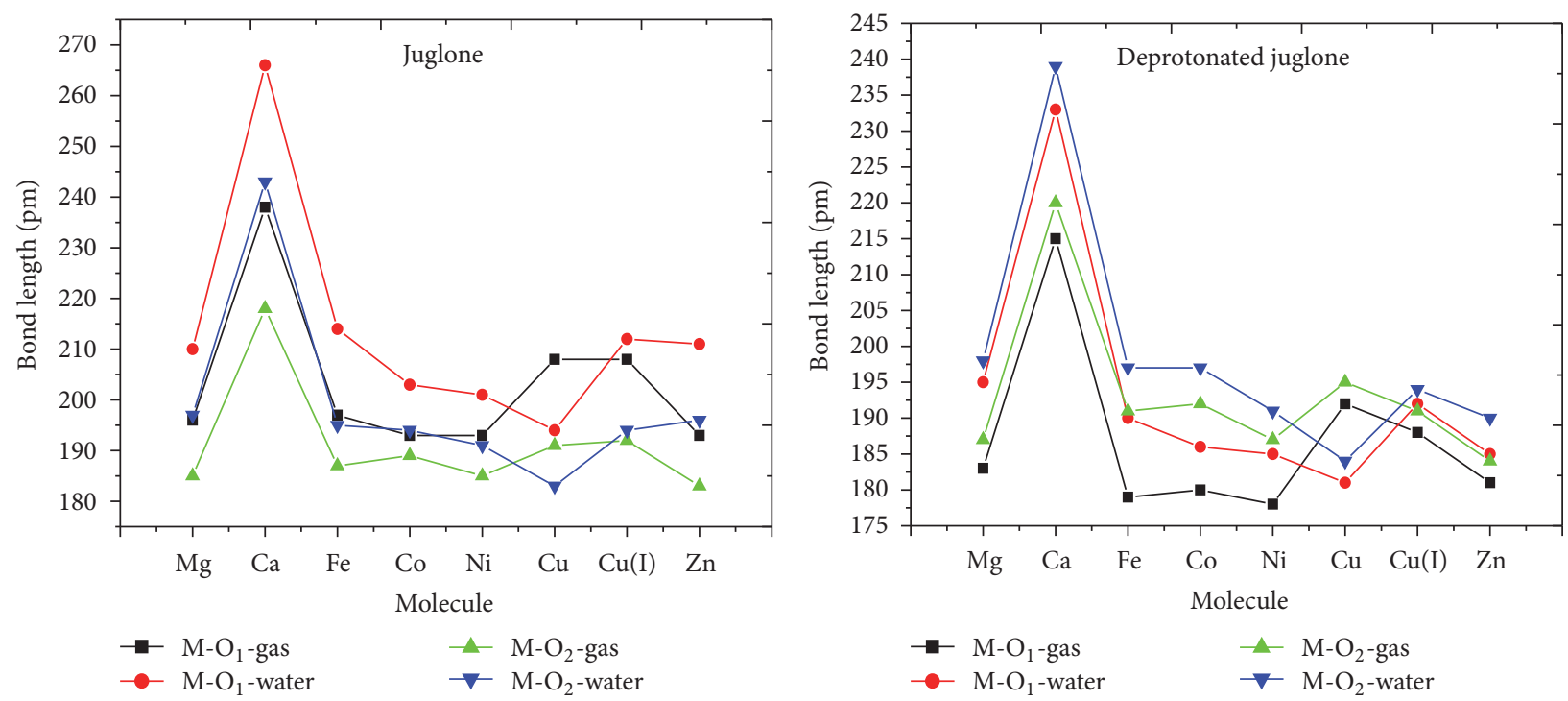

FIGURE 3: Variation of the metal-oxygen bond lengths $(\mathrm{pm})$ of the studied chelates obtained from the optimized geometries at DFT/B3LYP/6$31+(\mathrm{d}, \mathrm{p})$ level.

TABLE 3: Thermodynamic parameters $(\mathrm{kJ} / \mathrm{mol})$, atomic charge of the central metal(e) (ligand-metal charge transfer), and the correlation coefficient $\left(R^{2}\right)$ all obtained at B3LYP/6-31+G(d,p) level.

\begin{tabular}{|c|c|c|c|c|c|c|c|c|c|c|}
\hline & \multicolumn{5}{|c|}{ Juglone } & \multicolumn{5}{|c|}{ Deprotonated juglone } \\
\hline & $\mathrm{M}(\mathrm{e})$ & $\Delta H$ & $\Delta G$ & $\Delta E$ & $R^{2}$ & $\mathrm{M}(\mathrm{e})$ & $\Delta H$ & $\Delta G$ & $\Delta E$ & $R^{2}$ \\
\hline \multicolumn{11}{|l|}{ Gas } \\
\hline $\operatorname{Mg}(\mathrm{II})$ & $1.84(0.16)$ & -674.1 & -640.4 & -672.2 & \multirow{8}{*}{0.746} & $1.76(0.24)$ & -1623.6 & -1582.4 & -1618.5 & \multirow{8}{*}{0.639} \\
\hline $\mathrm{Ca}(\mathrm{II})$ & $1.93(0.07)$ & -416.1 & -384.1 & -415.1 & & $1.88(0.12)$ & -1275.3 & -1237.6 & -1227.2 & \\
\hline $\mathrm{Fe}(\mathrm{II})$ & $1.58(0.42)$ & -769.6 & -735.7 & -767.5 & & $1.43(0.57)$ & -1776.1 & -1735.3 & -1773.6 & \\
\hline $\mathrm{Co}(\mathrm{II})$ & $1.51(0.49)$ & -838.9 & -805.9 & -837.9 & & $1.28(0.72)$ & -1851.3 & -1811.9 & -1853.8 & \\
\hline $\mathrm{Ni}(\mathrm{II})$ & $1.31(0.69)$ & -945.1 & -915.7 & -945.6 & & $1.17(0.83)$ & -1966.5 & -1926.7 & -1963.0 & \\
\hline $\mathrm{Cu}(\mathrm{II})$ & $1.08(0.92)$ & -1027.0 & -996.0 & -1027.0 & & $0.97(1.03)$ & -2038.6 & -2001.4 & -2036.9 & \\
\hline $\mathrm{Cu}(\mathrm{I})$ & $0.89(0.11)$ & -244.8 & -214.1 & -244.7 & & $0.81(0.19)$ & -772.7 & -733.5 & -769.0 & \\
\hline $\mathrm{Zn}(\mathrm{II})$ & $1.66(0.34)$ & -841.5 & -808.3 & -841.6 & & $1.55(0.45)$ & -1841.0 & -1801.1 & -1838.7 & \\
\hline \multicolumn{11}{|l|}{ Water } \\
\hline $\operatorname{Mg}(\mathrm{II})$ & $1.93(0.07)$ & -48.6 & -14.1 & -46.1 & \multirow{8}{*}{0.853} & $1.89(0.11)$ & -209.1 & -168.2 & -205.2 & \multirow{8}{*}{0.871} \\
\hline $\mathrm{Ca}(\mathrm{II})$ & $1.98(0.02)$ & 9.4 & 39.3 & 10.6 & & $1.96(0.04)$ & -103.2 & -62.4 & -99.4 & \\
\hline $\mathrm{Fe}(\mathrm{II})$ & $1.85(0.15)$ & -51.1 & -15.0 & -49.5 & & $1.74(0.26)$ & -239.9 & -197.3 & -235.5 & \\
\hline $\mathrm{Co}(\mathrm{II})$ & $1.80(0.20)$ & -94.7 & -58.9 & -92.2 & & $1.66(0.34)$ & -262.2 & -221.1 & -259.8 & \\
\hline $\mathrm{Ni}(\mathrm{II})$ & $1.76(0.24)$ & -117.9 & -81.7 & -115.3 & & $1.58(0.42)$ & -321.6 & -280.7 & -317.2 & \\
\hline $\mathrm{Cu}(\mathrm{II})$ & $1.49(0.51)$ & -368.7 & -333.4 & -366.4 & & $1.37(0.63)$ & -630.8 & -590.2 & -627.7 & \\
\hline $\mathrm{Cu}(\mathrm{I})$ & $0.98(0.02)$ & -92.2 & -567.4 & -90.0 & & $0.86(0.14)$ & -222.6 & -185.2 & -219.5 & \\
\hline $\mathrm{Zn}(\mathrm{II})$ & $1.88(0.12)$ & -63.1 & -27.7 & -62.8 & & $1.77(0.23)$ & -242.4 & -203.8 & -239.5 & \\
\hline
\end{tabular}

the $\mathrm{Cu}(\mathrm{II})$ chelate is the most favorable, since it has the lowest free energy of formation $(-996 \mathrm{~kJ} / \mathrm{mol})$ in gas phase. The negative values of the binding (interaction) energies of all the juglone chelates are indicative of high stability of these molecules in the gas phase. The gas phase binding energies of the juglone chelates decrease in the order: $\mathrm{Cu}(\mathrm{I})>\mathrm{Ca}$ (II) $>\mathrm{Mg}(\mathrm{II})>\mathrm{Fe}(\mathrm{II})>\mathrm{Co}(\mathrm{II})>\mathrm{Zn}$ (II) $>\mathrm{Ni}(\mathrm{II})>\mathrm{Cu}(\mathrm{II})$. This ranking is in good agreement with the relative affinity of the metal ion to nonmetal atoms or anions proposed by Williams and Fraústo [33] for the first row transition elements. It is evidenced from Table 3 that water as solvent greatly increases the values of the said thermodynamic parameters. Indeed, in water the formation of the $\mathrm{Ca}$ (II) chelate is even endothermic and endergonic. Besides the $\mathrm{Ca}$ (II) chelate, the interaction energies of all the other chelates remain negative in aqueous phase, although they greatly increase in magnitude. The least 
$\Delta E$ difference between the aqueous and gas phases is found to be $154 \mathrm{~kJ} / \mathrm{mol}$ for $\mathrm{Cu}(\mathrm{I})$, whereas the highest $(830 \mathrm{~kJ} / \mathrm{mol})$ is observed for the $\mathrm{Ni}$ (II) chelate. Like in gas phase, the $\mathrm{Cu}$ (II) remains the metal ion with the highest affinity toward juglone (i.e., the chelate with the lowest binding energy).

It is also clear from Table 3 that the formation of all the chelates of deprotonated juglone is thermodynamically favorable, since it is exothermic and spontaneous in gas and aqueous phases. Furthermore, these chelates are all stable since their binding energies are negative in both media. In each of these study media, the values of $\Delta H, \Delta G$, and $\Delta E$ are more negative relative to those of juglone chelates. This result agrees with those obtained by Leopoldini and coworkers [11] in the study of iron chelation by Quercetin. In both media, $\mathrm{Cu}$ (II) is still found to be the metal with the highest affinity toward deprotonated juglone, while $\mathrm{Cu}(\mathrm{I})$ and $\mathrm{Ca}$ (II) also remain the metals with the lowest affinity to the ligand in the gas and the aqueous phases, respectively. As is the case with juglone chelates, the presence of water as solvent also leads to an increase in the $\Delta H, \Delta G$, and $\Delta E$ values of deprotonated juglone chelates.

The NPA charges on the central metal ions of the different chelates presented in Table 3 show that the charges on the metals are lower than their formal charges, which are +2 or +1 . This implies that ligand-metal charge transfer is effective. From the difference between the formal and actual charges on the central metal ions (presented in brackets in Table 2), it has been found that the highest ligand-metal charge transfer is obtained for $\mathrm{Cu}$ (II) in both gas and aqueous phases. This result is in good agreement with the high stability observed with the $\mathrm{Cu}$ (II) chelates. In addition, the charges carried by the metals in deprotonated juglone chelates are lower than those on the metals in juglone chelates, which is also in good agreement with their binding energy values. Moreover, ligand-metal charge transfer has been found to decrease from gas to aqueous phase, in conformity with the increment in the values of $\Delta H, \Delta G$, and $\Delta E$ observed in water. In order to determine the relationship between the ligand-metal charge transfer and the interaction energies, a linear plot between the two parameters has been done. The values of the correlation coefficient $\left(R^{2}\right)$ reported in Table 3 are all higher than 0.6. Better correlation coefficients are obtained in water, wherein $R^{2}$ values of 0.853 and 0.871 are calculated for the chelates of juglone and deprotonated juglone, respectively. From the foregoing results, it can be concluded that both the neutral and anionic forms of juglone can be efficiently used in the fight against metal ions toxicity and the adverse effects of metal overload in foods, polymers, and living organisms.

3.4. QTAIM Analysis of the M-O Bond Characters. Among the several techniques used in studying bonding interactions in molecules, those based on electron density analysis are the most reliable because electron density $(\rho(\mathbf{r}))$ is an observable. Bader's atoms in molecules method is one of the most used for this purpose, since it is based on $\rho(\mathbf{r})$ and its Laplacian $\left(\nabla^{2} \rho(\mathbf{r})\right)[31,34]$. This method also known as Bader's topological analysis, specifically studies $\rho(\mathbf{r})$ and $\nabla^{2} \rho(\mathbf{r})$ at the bond critical points (BCP), a BCP being a region between a pair of nuclei, where $\nabla \rho(\mathbf{r})=0$. Generally, the character of a chemical interaction is determined based on the following criteria at the BCPs [35-37]:

(i) high values of $\rho(\mathbf{r}), \nabla^{2} \rho(\mathbf{r})<0$, and $[-g(\mathbf{r}) / v(\mathbf{r})]<1$ are associated with covalent bonds (shared interactions);

(ii) low values of $\rho$ (r) (generally less than 0.1 a.u.), $\nabla^{2} \rho(\mathbf{r})$ $>0$, and $0.5<[-g(\mathbf{r}) / v(\mathbf{r})]<1$ signify intermediate type interactions such as polar covalent bonds, strong hydrogen bonds, and coordination bonds;

(iii) low values of $\rho(\mathbf{r})$ (typically less than 0.1 a.u.), $\nabla^{2} \rho(\mathbf{r})$ $>0$, and $[-g(\mathbf{r}) / v(\mathbf{r})]>1$ are associated with closed shell interactions (weak interactions) like ionic, weak hydrogen and van der Waals interactions.

Here, $g(\mathbf{r})$ is the kinetic energy density at the BCP (always positive), while $v(\mathbf{r})$ is the potential energy density at the BCP (always negative). The above-mentioned criteria were exploited in this research endeavor to evaluate the characters of the M-O bonds. For all the chelates, the Poincaré-Hopf relation was fulfilled [31]. Our calculated values of these parameters are reported in Table 4.

From Table 4, it can be seen that the M-O bonds in the $\mathrm{Mg}(\mathrm{II})$ and $\mathrm{Ca}$ (II) chelates are characterized by low values of $\rho(\mathbf{r}), \nabla^{2} \rho(\mathbf{r})>0$, and $[-g(\mathbf{r}) / v(\mathbf{r})]>1$; hence, they are weak interactions. In the case of the $\mathrm{M}-\mathrm{O}$ bonds in the rest of the chelates, the values of $\rho(\mathbf{r})$ are low, $\nabla^{2} \rho(\mathbf{r})>0$, and 0.5 $<[-g(\mathbf{r}) / v(\mathbf{r})]<1$, meaning that they are intermediate type interactions. These observations are similar in both gas and aqueous phases, although the values of the parameters change slightly.

For the juglone chelates, the $\rho(\mathbf{r})$ values of the $\mathrm{O}_{2}-\mathrm{M}$ bonds are found to be higher than those of the $\mathrm{O}_{1}-\mathrm{M}$ bonds, supporting the fact that the former bonds are shorter than the latter. The reverse trend is observed for the chelates of deprotonated juglone because the $\mathrm{O}_{1}$ atom carries a negative charge, which increases electron density around the $\mathrm{O}_{1}-\mathrm{M}$ bonds. As evidenced from Table 3, the electron density at the $\mathrm{BCPs}$ of the $\mathrm{M}-\mathrm{O}$ bonds reduces ongoing from gas to aqueous phase, matching with the increase in their bond lengths from gas to aqueous phase as previously observed in Section 3.3. From the values of $\rho(\mathbf{r}), \nabla^{2} \rho(\mathbf{r})$, and $[-g(\mathbf{r}) / v(\mathbf{r})]$, it is clear that the $\mathrm{O}-\mathrm{H}$ bonds are covalent in nature. The electron densities on all the $\mathrm{O}-\mathrm{H}$ bonds are nearly the same and lie between 0.344 and 0.357 in gas phase and between 0.348 and 0.354 in water. This serves as a plausible explanation for the small discrepancies observed in the $\mathrm{O}-\mathrm{H}$ bond lengths of the compounds (Section 3.3). In this light, the slight reductions in the lengths of these bonds in water are attributable to the slight changes in their $\rho(\mathbf{r})$ values.

3.5. Radical Scavenging Activity. Motivated by the stability of the juglone chelates as earlier revealed by studies carried out on thermodynamic parameters and binding energies, we have studied the different mechanisms of hydrogen atom transfer by antioxidants in order to investigate the effect of the metal ions studied on the radical scavenging activity of juglone. The values of the parameters describing these mechanisms, calculated using (8)-(12), are reported in Table 5. The gas 
TABLE 4: Topological characteristics at the BCPs of the O-M and O-H bonds of the chelates.

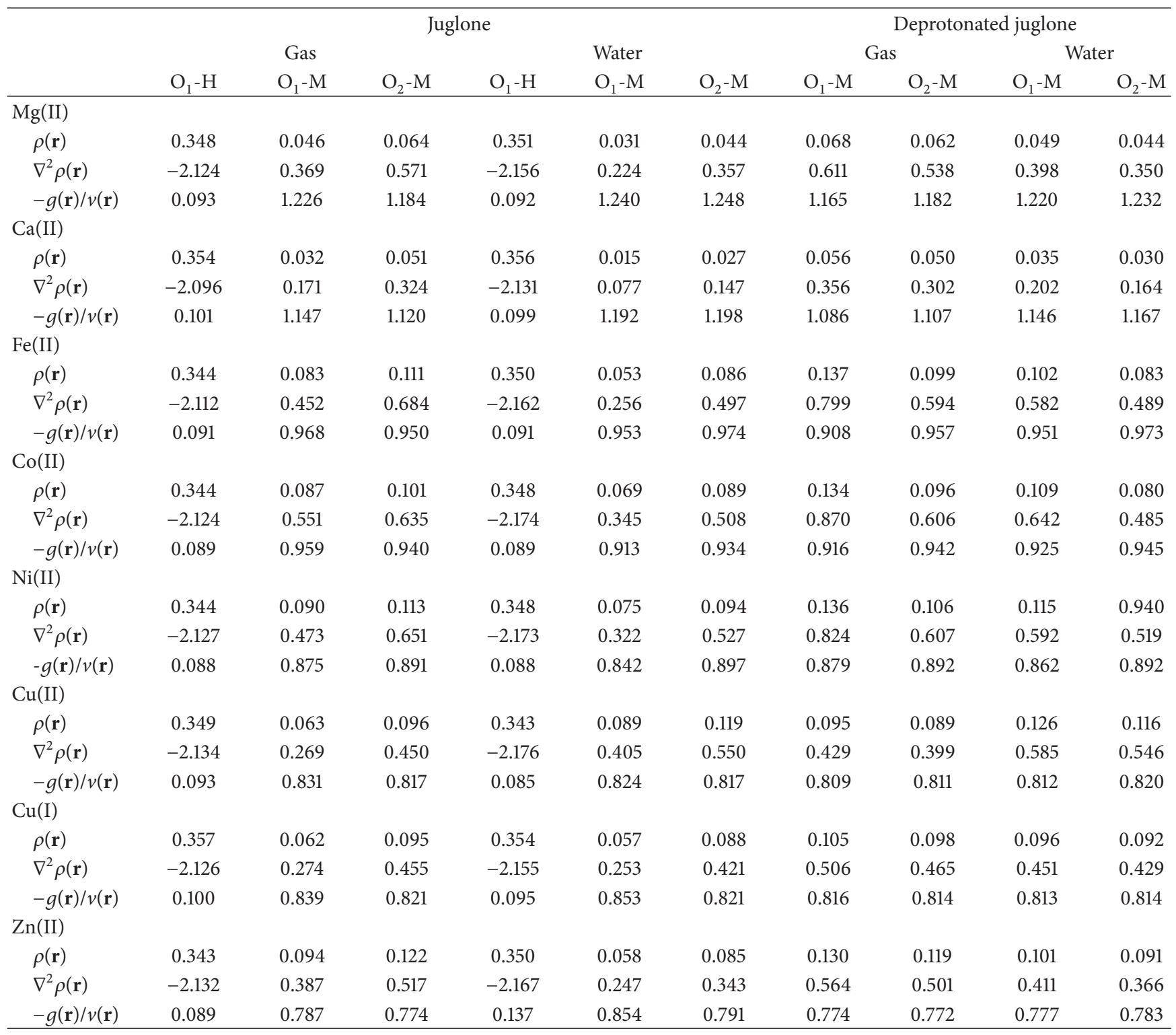

phase enthalpy and free energy of electron employed here are $3.145 \mathrm{~kJ} / \mathrm{mol}$ and $-3.42 \mathrm{~kJ} / \mathrm{mol}$, respectively [38]. In water, the values $-105 \mathrm{~kJ} / \mathrm{mol}[39]$ and $-156.8 \mathrm{~kJ} / \mathrm{mol}[40]$ for the enthalpy and the free energy of electron, respectively, were used. On the other hand, the enthalpies of formation for the proton in gas phase and water are $6.197 \mathrm{~kJ} / \mathrm{mol}[38]$ and $-1022 \mathrm{~kJ} / \mathrm{mol}$ [39], respectively. The values of the proton hydration free energies in these media are, respectively, $-26.26 \mathrm{~kJ} / \mathrm{mol}[38]$ and $-1104.5 \mathrm{~kJ} / \mathrm{mol}[40]$.

3.5.1. Direct Hydrogen Atom Transfer Mechanism. The BDE and BDFE values presented in Table 4 are all positive, indicating that this mechanism is endothermic and nonfavorable at $298.15 \mathrm{~K}$ and $1 \mathrm{~atm}$. To facilitate the analysis of BDE and BDFE, their values have been plotted in the graphs shown in Figure 4. It is clear from this figure that the BDE and BDFE values of the chelates are lower than that of juglone in the two media investigated. This is a clear indication of the fact that the presence of these metal ions increases the AOA of juglone, which is in good agreement with the findings in the literature $[9,26]$. In gas phase, the $\mathrm{Co}(\mathrm{II})$ chelate has been found to possess the lowest BDE value $(262 \mathrm{~kJ} / \mathrm{mol})$, which corroborates with its highest $\mathrm{O}-\mathrm{H}$ bond length observed in the said phase (Section 3.3). The BDE values of the chelates studied are found to increase in the order: $\mathrm{Co}<\mathrm{Fe}<\mathrm{Zn}<$ $\mathrm{Mg}=\mathrm{Ni}<\mathrm{Ca}<\mathrm{Cu}(\mathrm{II})<\mathrm{Cu}(\mathrm{I})$. This ranking shows that the copper chelates are the least reactive in gas phase. This low AOA may be attributed to the observed low electron spin density distribution in the radicals of these copper chelates, as shown in Figure 5. This figure shows a huge distribution of electron spin density in the two most reactive chelates (Co and Fe chelates), which stabilizes the radical. 


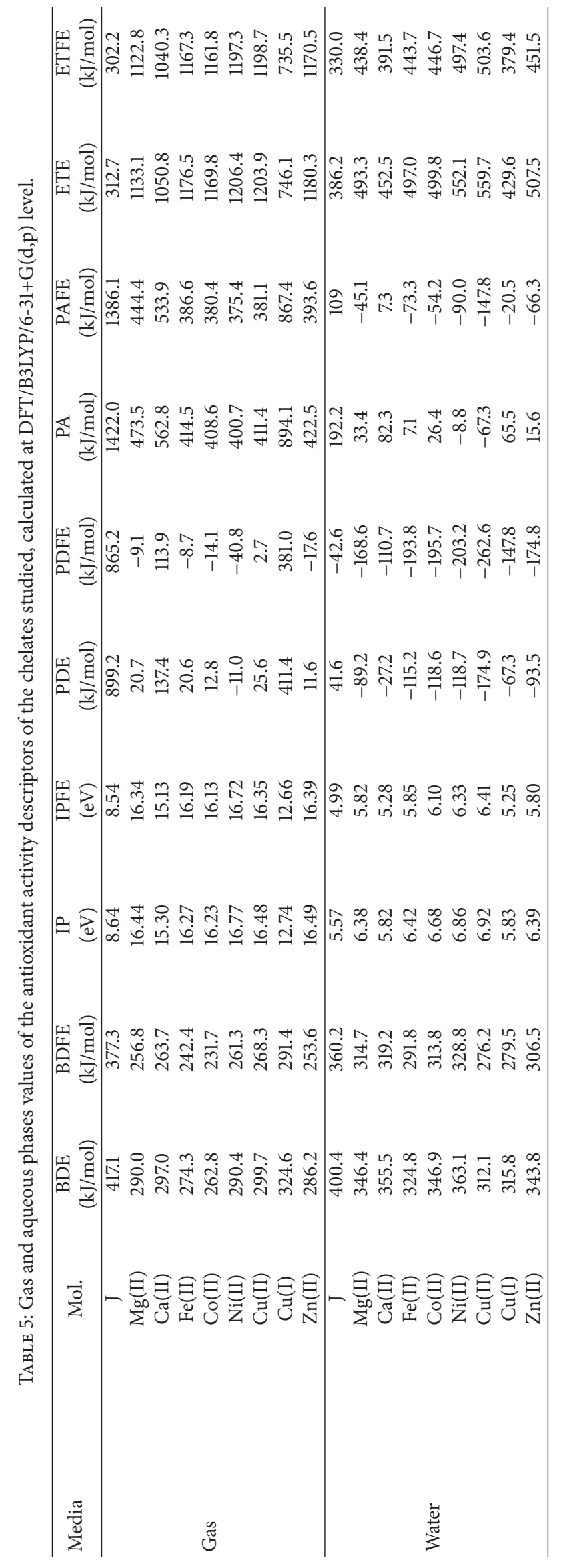




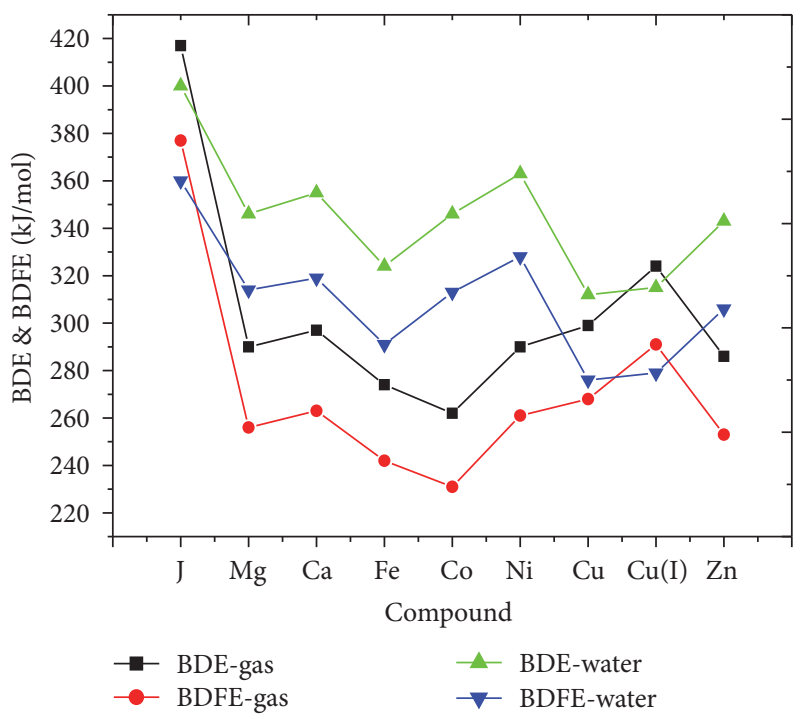

FIGURE 4: Superposition of BDE and BDFE of the studied chelates in gas and aqueous phases.

Apart from the $\mathrm{Cu}(\mathrm{I})$ chelate, the $\mathrm{BDE}$ values of the other chelates increase in water as shown in Figure 3. This result agrees with the slight decrease in the $\mathrm{O}-\mathrm{H}$ bond length (and the increase for the $\mathrm{Cu}$ chelates) previously observed. As a result of the $\mathrm{O}-\mathrm{H}$ bond length variations ongoing from gas phase to water, the $\mathrm{Cu}(\mathrm{II})$ chelate has the lowest $\mathrm{BDE}$ value $(312 \mathrm{~kJ} / \mathrm{mol})$ in water and is thus the best antioxidant among those studied. The BDE values in water are in the order: $\mathrm{Cu}(\mathrm{II})<\mathrm{Cu}(\mathrm{I})<\mathrm{Fe}<\mathrm{Zn}<\mathrm{Mg}=\mathrm{Co}<\mathrm{Ca}<\mathrm{Ni}$. It is clear from Figure 3 that the BDE and BDFE values of the chelates follow the same trend in both gas and aqueous phases.

3.5.2. Electron Transfer-Proton Transfer Mechanism. IP is the first and the determining step of this mechanism. The IP and IPFE values of the chelates reported in Table 4 are plotted in Figure 6. As depicted in this figure, IP and IPFE like BDE and BDFE follow the same trend in both gas and aqueous phases. However, the differences between IPs and IPFEs are very small compared to those between BDEs and BDFEs in a given milieu. It can also be seen from Table 5 that the IP values are higher than BDEs in gas and aqueous phases. It is evident from Figure 4 that, in gas phase, the presence of the metal ions leads to a great increment in the IP value of juglone. This result agrees with those obtained by other authors in similar studies $[9,26]$. In gas phase, the $\mathrm{Cu}(\mathrm{I})$ chelate has the lowest IP value $(12.74 \mathrm{eV})$. Although the IPs and IPFEs of all molecules greatly decrease in presence of water, the IP values of the chelates are close to that of juglone in the solvent phase, whereas in gas phase the IP values of the chelates are significantly higher than that of juglone. In water phase, the $\mathrm{Cu}(\mathrm{I})$ chelate still has the lowest IP value $(5.83 \mathrm{eV})$.

Also presented in Table 4 are the PDE and PDFE values of the chelates. The PDE values are found to be much lower than that of juglone, with that of the Ni chelate being even negative $(-11 \mathrm{~kJ} / \mathrm{mol})$. From this result, it is clear that the cationic radicals obtained from the chelates are very reactive.
The PDFE values show that the proton transfer reaction by the cationic radicals of the $\mathrm{Mg}, \mathrm{Fe}, \mathrm{Co}, \mathrm{Ni}$, and $\mathrm{Zn}$ chelates is exergonic in gas phase. A close inspection of Table 4 also shows that, in water, the PDE and PDFE values of all the chelate are negative, meaning that the reaction is spontaneous under standard conditions. This is certainly due to the low values of the enthalpy and free energy of proton in water.

\subsubsection{Sequential Proton Loss Electron Transfer Mechanism.} The first step of this mechanism corresponds to a proton transfer by the antioxidant and is described by PA. Low PA value indicates a high acidic hydroxyl group and thus good AOA. The PA and PAFE values are presented in Table 4. For better comprehension of their analysis, the PA and PAFE values have been plotted and their trends are shown in Figure 7.

It is clear from Figure 6 that the PA values of the chelates are lower relative to that of juglone in gas and aqueous phases. This signifies that metal chelation increases the acidity of the $\mathrm{OH}$ group. This result is in good agreement with those obtained by Holtomo and coworkers [9]. In gas phase, the PA values of the chelates increase in the order: $\mathrm{Ni}(\mathrm{II})<$ $\mathrm{Co}$ (II) $<\mathrm{Cu}$ (II) $<\mathrm{Fe}$ (II) $<\mathrm{Zn}$ (II) $<\mathrm{Mg}$ (II) $<\mathrm{Ca}$ (II) $<\mathrm{Cu}$ (I) . According to this ranking, the highest acidity of the $\mathrm{O}-\mathrm{H}$ group of juglone in gas phase is obtained in the presence of the $\mathrm{Ni}(\mathrm{II})$ ion. In aqueous solution, the PA and PAFE values are found to decrease due to the low values of the enthalpy and free energy of proton in water. In this solvent, the PA values of the $\mathrm{Ni}(\mathrm{II})$ and $\mathrm{Cu}(\mathrm{II})$ chelates are even negative, indicating that the proton transfer reactions by these chelates are exothermic. It can be seen from Table 5 that, apart from the Ca (II) chelate, the PAFE values of other chelates are negative in water, showing that the reaction is spontaneous. In water, the PA values of the chelates are found to increase in the order: $\mathrm{Cu}(\mathrm{II})<\mathrm{Ni}(\mathrm{II})<\mathrm{Fe}(\mathrm{II})<\mathrm{Zn}$ (II) $<\mathrm{Co}(\mathrm{II})<$ $\mathrm{Mg}(\mathrm{II})<\mathrm{Cu}(\mathrm{I})<\mathrm{Ca}(\mathrm{II})$. Based on this classification, it can be concluded that the $\mathrm{Cu}(\mathrm{II})$ chelate is the most acidic. From Figure 7, it can be seen that PA and PAFE values follow the same trend in the two study milieus. From Table 5, it can also be observed that the PA and PAFE values are always higher than the PDE and PDFE values, buttressing the higher reactivity of the cationic radicals.

The ETE and ETFE values describing the electron transfer reaction by the anions are presented in Table 4 . These values revealed that, in gas phase and water, ETEs and ETFEs are lower than IPs and IPFEs. The ETE and ETFE values can be used to describe the AOA of the chelate formed from deprotonated juglone, since these molecules no longer contain any hydroxyl group. Indeed, by comparing the ETE values of the said chelates and the IP value of juglone in gas phase, it can be concluded that the only chelate which could be considered to be a better reducing agent than juglone is that of $\mathrm{Cu}(\mathrm{I})$. In water, however, the ETE values of the chelates are lower than the IP value of juglone except for the $\mathrm{Cu}(\mathrm{II})$ chelate. This means that nearly all of the deprotonated juglone chelates are better reducing agents and as such are better antioxidants than juglone in water. The ETEs and ETFEs values follow the same trend in both media, thus leading to the same conclusions. 

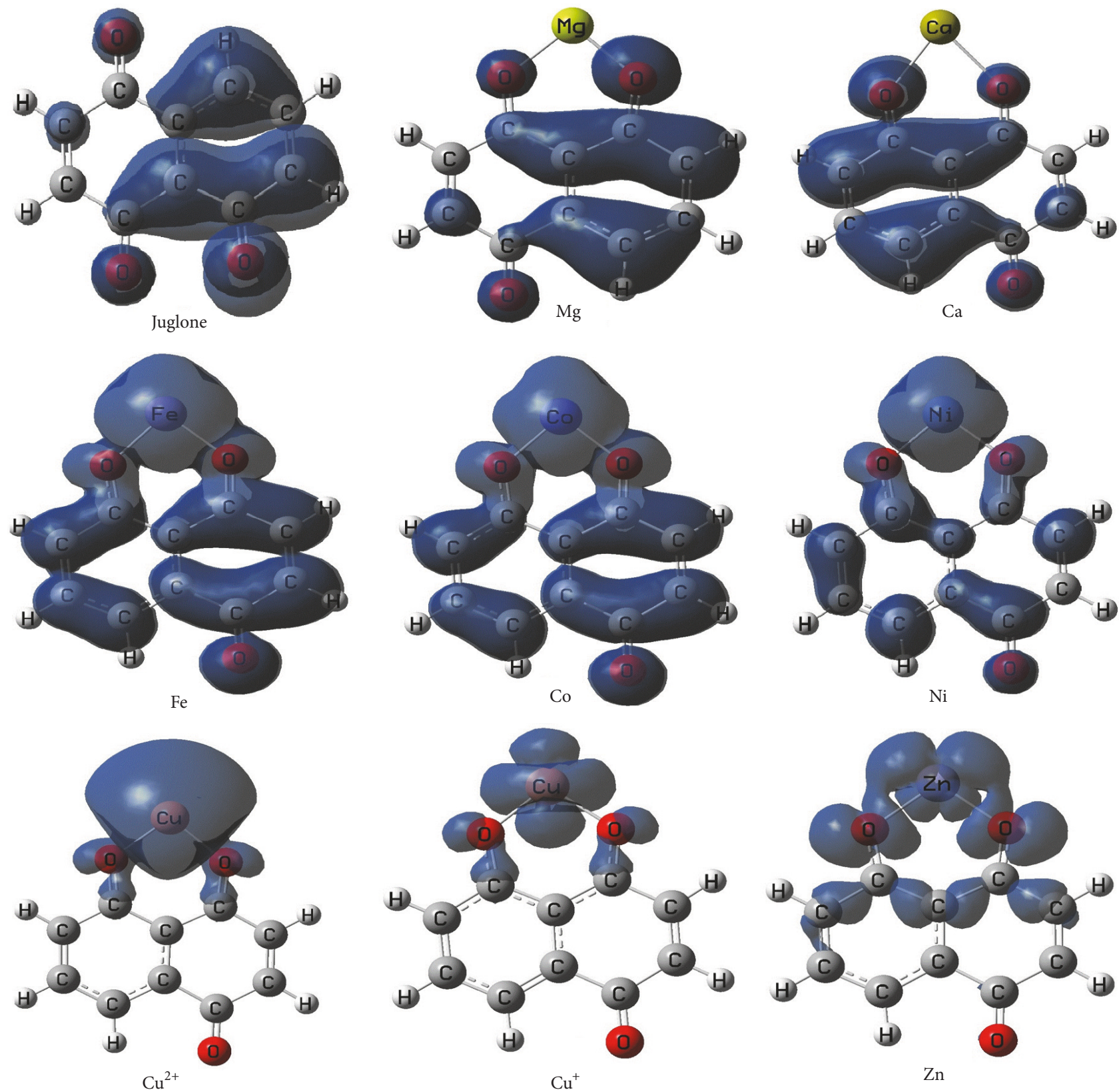

FIGURE 5: Spin density distribution for the radical formed from the chelates after the hydrogen atom abstraction, obtained at isovalue $=0.04$.

3.5.4. Thermodynamic Preferred Mechanism. To determine the thermodynamically preferred mechanism of the juglone chelates, the free energies of the first steps of the hydrogen transfer mechanisms have been plotted in the graphs shown in Figure 8.

The following ranking of the free energies for the first step reactions of the chelates in gas phase, $\mathrm{BDFE}<\mathrm{PAFE}<\mathrm{IPFE}$, is obvious from Figure 8. According to this classification, the direct HAT is the preferred mechanism in the gas phase for neutral juglone and its chelates. Figure 8 also shows that, in gas phase, the chelates are more reactive than the ligand, the Co chelate being the most reactive. From the graph in Figure 8 , the following ranking of free energies can be made in water as solvent for all the compounds: PAFE $<$ BDFE $<$ IPFE. This shows that the sequential proton loss electron transfer is the preferred mechanism in water. This result is in good agreement with those found in the literature with the polar solvents [41-48]. In water, the $\mathrm{Cu}$ (II) chelate is found to be the most stable and the most reactive.

\section{Conclusion}

In this paper, the antioxidant activity of neutral and deprotonated juglone has been investigated in the gas and the aqueous phases at DFT/B3LYP/6-31+G(d,p) level of theory. In this regard, the chelating ability of these ligands toward $\mathrm{Mg}^{2+}$, 


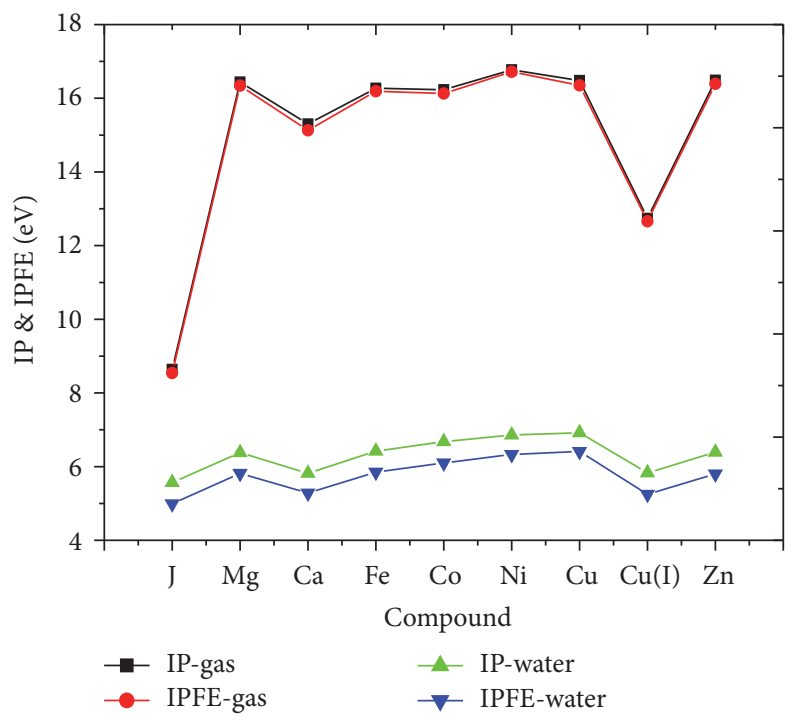

FIGURE 6: Superposition of IP and IPFE of the studied chelates in gas and aqueous phases.

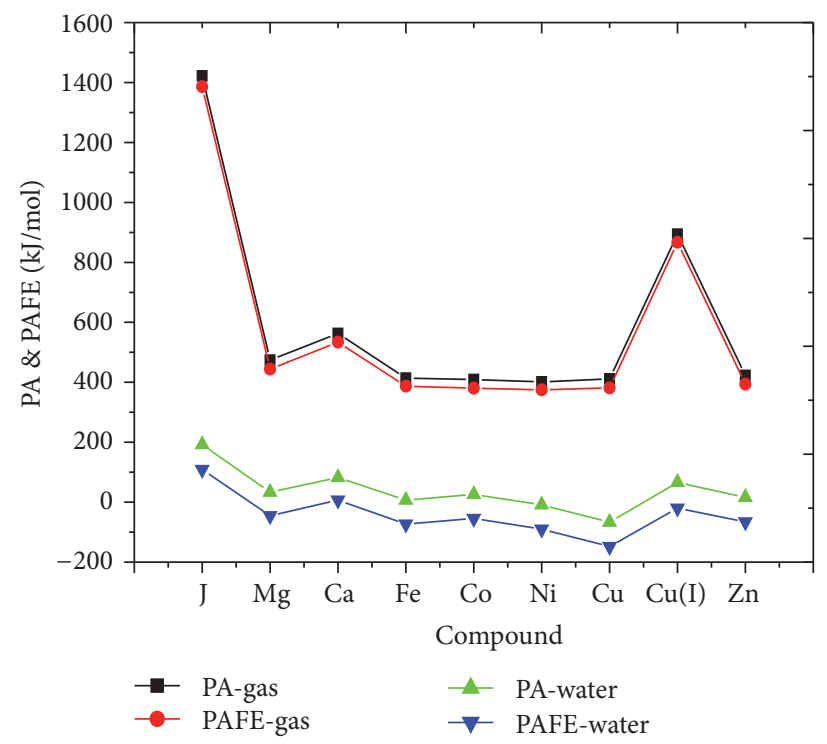

FIGURE 7: Superposed values of PA and PAFE of the chelates studied in the gas and the aqueous phases.

$\mathrm{Ca}^{2+}, \mathrm{Fe}^{2+}, \mathrm{Co}^{2+}, \mathrm{Ni}^{2+}, \mathrm{Cu}^{2+}, \mathrm{Cu}^{+}$, and $\mathrm{Zn}^{2+}$ ions usually involved in the generation of free radicals in living organisms was studied. Furthermore, the effect of these metals on the radical scavenging activity of neutral juglone was investigated by means of the usual hydrogen atom transfer mechanisms. The analysis of the thermodynamic parameters $(\Delta H$ and $\Delta G)$ and the interaction energies calculated herein showed that the neutral and anionic forms of juglone are capable of chelating these metal ions in gas and aqueous phases. For both ligands, the highest metal ion affinity has been exhibited toward the $\mathrm{Cu}$ (II) ions. This trend has been confirmed by the fact that the highest reduction effect due to chelation is observed for the $\mathrm{Cu}$ (II) chelate. Bader's topological analyses revealed that the metal-ligand bonds in the $\mathrm{Mg}$ and $\mathrm{Ca}$ chelates are weak interactions, while those in the other chelates are intermediate type interactions, in both gas and aqueous phases. Analyses of the BDE, IP, and PA along with their free energies showed that direct HAT transfer is the preferred AOA mechanism of the neutral juglone chelates in gas phase, with the $\mathrm{Co}(\mathrm{II})$ chelate being the most reactive. In water, sequential proton transfer electron transfer has been found to be the most preferred AOA mechanism, for which the $\mathrm{Cu}(\mathrm{II})$ chelate is found to be the most reactive. However, to gain further insight into the antioxidant mechanisms of the molecules currently studied, we intend to perform kinetic studies on the molecules. 

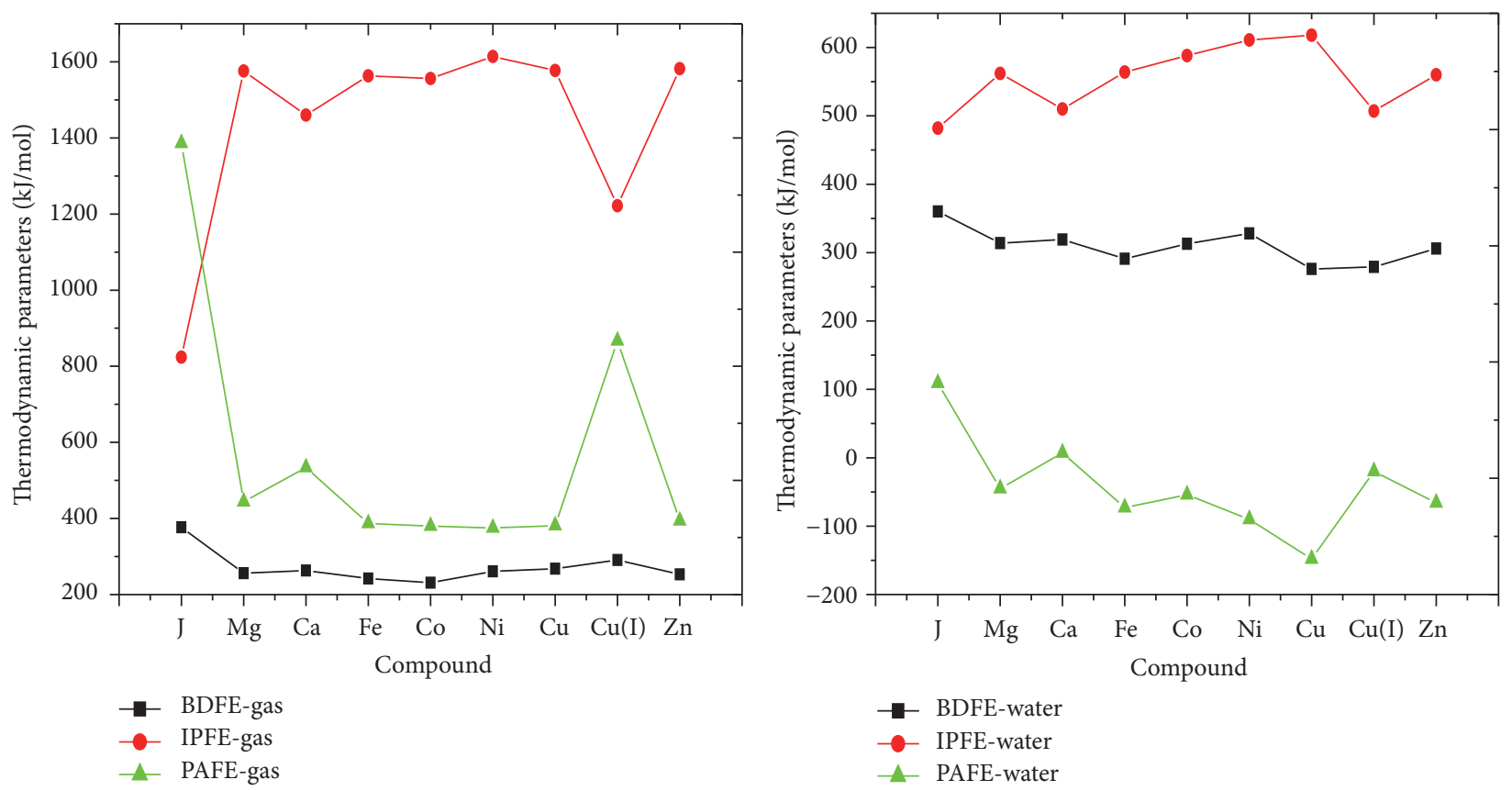

FIGURE 8: Superposed values of BDFE, IPFE, and PAFE of the chelates of neutral juglone in gas and aqueous phases.

\section{Conflicts of Interest}

The authors declare that there are no conflicts of interest regarding the publication of this paper.

\section{Acknowledgments}

The work has been supported by the annual research grant of the Laboratory of Noxious Chemistry and Environmental Engineering of the University of Dschang, Cameroon. It also benefited from the financial assistance of the Ministry of External Affairs of India and FICCI (Federation of Indian Chambers of Commerce and Industry) through a CV Raman International Fellowship award (Grant no. 101F102) for African Researchers that was realized at IIT Kanpur, Kanpur, India.

\section{References}

[1] S. S. Gill and N. Tuteja, "Reactive oxygen species and antioxidant machinery in abiotic stress tolerance in crop plants," Plant Physiology and Biochemistry, vol. 48, no. 12, pp. 909-930, 2010.

[2] V. Chobot and F. Hadacek, "Iron and its complexation by phenolic cellular metabolites: from oxidative stress to chemical weapons," Plant Signaling and Behavior, vol. 5, no. 1, pp. 4-8, 2010.

[3] E. A. Decker, J. E. Ryan, and D. J. Mc Clements, Oxidation in Foods And Beverages and Antioxidant Applications, Wood Head Publishing Limited, New Dehli, India, 2010.

[4] M. Valko, D. Leibfritz, J. Moncol, M. T. D. Cronin, M. Mazur, and J. Telser, "Free radicals and antioxidants in normal physiological functions and human disease," International Journal of Biochemistry and Cell Biology, vol. 39, no. 1, pp. 44-84, 2007.
[5] K. M. Lincoln, T. E. Richardson, L. Rutter, P. Gonzalez, J. W. Simpkins, and K. N. Green, "An N-heterocyclic amine chelate capable of antioxidant capacity and amyloid disaggregation," ACS Chemical Neuroscience, vol. 3, no. 11, pp. 919-927, 2012.

[6] M. Leopoldini, N. Russo, and M. Toscano, "The molecular basis of working mechanism of natural polyphenolic antioxidants," Food Chemistry, vol. 125, no. 2, pp. 288-306, 2011.

[7] I. Gülçin, Z. Huyut, M. Elmastaş, and H. Y. Aboul-Enein, "Radical scavenging and antioxidant activity of tannic acid," Arabian Journal of Chemistry, vol. 3, no. 1, pp. 43-53, 2010.

[8] Y. Qiu, Z. Wang, A. C. E. Owens et al., "Antioxidant chemistry of graphene-based materials and its role in oxidation protection technology," Nanoscale, vol. 6, no. 20, pp. 11744-11755, 2014.

[9] O. Holtomo, M. Nsangou, J. J. Fifen, Z. Dhaouadi, and O. Motapon, "Antioxidative potency and UV-Vis spectra features of the compounds resulting from the chelation of $\mathrm{Fe}^{2+}$ by caffeic acid phenethyl ester and two of its derivatives," Computational and Theoretical Chemistry, vol. 1067, pp. 135-147, 2015.

[10] M. M. Kabanda, V. T. Tran, K. M. Seema et al., "Conformational, electronic and antioxidant properties of lucidone, linderone and methyllinderone: DFT, QTAIM and NBO studies," Molecular Physics, vol. 113, no. 7, pp. 683-697, 2015.

[11] M. Leopoldini, N. Russo, S. Chiodo, and M. Toscano, "Iron chelation by the powerful antioxidant flavonoid quercetin," Journal of Agricultural and Food Chemistry, vol. 54, no. 17, pp. 6343-6351, 2006.

[12] T. Marino, M. Pavelka, M. Toscano, and N. Russo, "Structural and binding properties of metal ion chelators relevant to Alzheimer's disease. A theoretical investigation," International Journal of Quantum Chemistry, vol. 112, no. 9, pp. 2109-2114, 2012. 
[13] P. Mladěnka, K. Macáková, T. Filipský et al., "In vitro analysis of iron chelating activity of flavonoids," Journal of Inorganic Biochemistry, vol. 105, no. 5, pp. 693-701, 2011.

[14] N. R. Perron and J. L. Brumaghim, "A review of the antioxidant mechanisms of polyphenol compounds related to iron binding," Cell Biochemistry and Biophysics, vol. 53, no. 2, pp. 75-100, 2009.

[15] M. Leopoldini, T. Marino, N. Russo, and M. Toscano, "Antioxidant properties of phenolic compounds: $\mathrm{H}$-atom versus electron transfer mechanism," The Journal of Physical Chemistry A, vol. 108, no. 22, pp. 4916-4922, 2004.

[16] F. A. D. Tamafo, J. N. Ghogomu, M. D. Bikélé, N. K. Nkungli, and E. Younang, "Structural and antioxidant properties of compounds obtained from $\mathrm{Fe}^{2+}$ chelation by juglone and two of its derivatives: DFT, QTAIM, and NBO studies," Bioinorganic Chemistry and Applications, vol. 2016, Article ID 8636409, 13 pages, 2016.

[17] A. Galano, G. Mazzone, R. Alvarez-Diduk, T. Marino, J. R. Alvarez-Idaboy, and N. Russo, "The food antioxidants: chemical insights at the molecular level," Annual Review of Food Science and Technology, vol. 7, no. 1, pp. 335-352, 2016.

[18] R. Ditchfield, W. J. Hehre, and J. A. Pople, "Self-consistent molecular-orbital methods. IX. An extended gaussian-type basis for molecular-orbital studies of organic molecules," The Journal of Chemical Physics, vol. 54, no. 2, pp. 720-723, 1971.

[19] W. J. Hehre, K. Ditchfield, and J. A. Pople, "Self-consistent molecular orbital methods. XII. Further extensions of gaussiantype basis sets for use in molecular orbital studies of organic molecules," The Journal of Chemical Physics, vol. 56, no. 5, pp. 2257-2261, 1972.

[20] A. D. Becke, "Density-functional thermochemistry. III. The role of exact exchange," The Journal of Chemical Physics, vol. 98, no. 7, pp. 5648-5652, 1993.

[21] C. Lee, W. Yang, and R. G. Parr, "Development of the ColleSalvetti correlation-energy formula into a functional of the electron density," Physical Review B, vol. 37, no. 2, pp. 785-789, 1988.

[22] E. Lewars, Computational chemistry: Introduction to The Theory And Applications of Molecular and Quantum Mechanics, Klumer Academy Publishers, New York, NY, USA, 2003.

[23] F. Jensen, Introduction to Computational Chemistry, John Wiley \& Sons, New York, NY, USA, 1999.

[24] K. I. Ramachandran, G. Deepa, and K. Namboori, Computational Chemistryand Molecular Modeling : Principles and Applications, Springer, Berlin, Germany, 2008.

[25] M. J. Frisch, G. W. Trucks, H. B. Schlegel et al., Gaussian 09, Revision A.02, Gaussian, Inc, Wallingford, UK, 2009.

[26] J. J. Fifen, M. Nsangou, Z. Dhaouadi, O. Motapon, and S. Lahmar, "Single or double hydrogen atom transfer in the reaction of metal-associated phenolic acids with ${ }^{\circ} \mathrm{OH}$ radical: DFT study," Journal of Molecular Structure: THEOCHEM, vol. 901, no. 1-3, pp. 49-55, 2009.

[27] D. C. Young, Computational Chemistry: A Practical Guide for ApplyingTechniques to Real-World Problems, John Wiley and Sons Inc, New York, NY, USA, 2001.

[28] P. W. Atkins and R. S. Friedman, Molecular Quantum Mechanics, Oxford university press, Oxford, UK, 3rd edition, 1996.

[29] I. N. Levine, Quantum Chemistry, Printice Hall Inc, Upper Saddle River, NJ, USA, 5th edition, 2000.
[30] E. D. Glendening, R. L. Clark, and F. Weinhold, "Natural bond orbital methods," WIREs Compututational Molecular Sciences, vol. 2, pp. 1-42, 2012.

[31] R. F. W. Bader, Atoms in Molecules: A Quantum Theory, Oxford University Press, Oxford, UK, 1990.

[32] T. Lu and F. Chen, "Calculation of molecular orbital composition," Acta Chimica Sinica, vol. 69, no. 20, pp. 2393-2406, 2011.

[33] R. J. P. Williams and S. J. J. R. Fraústo, The Chemistry of Evolution, Elsevier, Amsterdam, The Netherland, 2006.

[34] P. L. A. Popelier, "On the full topology of the Laplacian of the electron density," Coordination Chemistry Reviews, vol. 197, no. 1, pp. 169-189, 2000.

[35] G. V. Baryshnikov, B. F. Minaev, V. A. Minaeva, A. T. Podgornaya, and H. Ågren, "Application of Bader's atoms in molecules theory to the description of coordination bondsin the complex compounds of $\mathrm{Ca}^{2+}$ and $\mathrm{Mg}^{2+}$ with methylidene rhodanine and its anion," Russian Journal of General Chemistry, vol. 82, no. 7, pp. 1254-1262, 2012.

[36] I. L. Kirby, M. Brightwell, M. B. Pitak, C. Wilson, S. J. Coles, and P. A. Gale, "Systematic experimental charge density analysis of anion receptor complexes," Physical Chemistry Chemical Physics, vol. 16, no. 22, pp. 10943-10958, 2014.

[37] N. Trendafilova, G. Bauer, and T. Mihaylov, "DFT and AIM studies of intramolecular hydrogen bonds in dicoumarols," Chemical Physics, vol. 302, no. 1-3, pp. 95-104, 2004.

[38] J. E. Bartmess, "Thermodynamics of the electron and the proton," The Journal of Physical Chemistry, vol. 98, no. 25, pp. 6420-6424, 1994.

[39] J. Rimarcik, V. Lukeš, E. Klein, and M. Ilčin, "Study of the solvent effect on the enthalpies of homolytic and heterolytic nh bond cleavage in $p$-phenylenediamine and tetracyano- $p$ phenylenediamine," Journal of Molecular Structure, vol. 952, no. 1-3, pp. 25-30, 2010.

[40] J. J. Fifen, Z. Dhaouadi, M. Nsangou, O. Holtomo, and N. Jaidane, "Proton-coupled electron transfer in the reaction of 3,4-dihydroxyphenylpyruvic acid with reactive species in various media," International Journal of Chemical Physics, vol. 2015, Article ID 835707, 13 pages, 2015.

[41] Z. Marković, D. Milenković, J. Đorović et al., "Free radical scavenging activity of morin $2^{\prime}-\mathrm{O}$ phenoxide anion," Food Chemistry, vol. 135, no. 3, pp. 2070-2077, 2012.

[42] M. Szeląg, A. Urbaniak, and H. A. R. Bluyssen, "A theoretical antioxidant pharmacophore for natural hydroxycinnamic acids," Open Chemistry, vol. 13, no. 1, pp. 17-31, 2015.

[43] Y. Chen, H. Xiao, J. Zheng, and G. Liang, "Structure-thermodynamics-antioxidant activity relationships of selected natural phenolic acids and derivatives: an experimental and theoretical evaluation," PLoS ONE, vol. 10, no. 3, Article ID e0121276, 2015.

[44] M. Najafi, "On the antioxidant activity of the Ortho and Meta substituted Daidzein derivatives in the gas phase and solvent environment," Journal of the Mexican Chemical Society, vol. 58, no. 1, pp. 36-45, 2014.

[45] N. M. Thong, D. T. Quang, N. H. T. Bui, D. Q. Dao, and P. C. Nam, "Antioxidant properties of xanthones extracted from the pericarp of Garcinia mangostana (Mangosteen): a theoretical study," Chemical Physics Letters, vol. 625, pp. 30-35, 2015.

[46] Z. Marković, J. Dorović, Dimitrić M. J. M., R. Biocanin, and D. Amic, "Comparative density functional study of antioxidative 
activity of the hydroxybenzoic acids and their anions," Turkish Journal of Chemistry, vol. 40, no. 3, pp. 499-509, 2016.

[47] G. Mazzone, N. Malaj, A. Galano, N. Russo, and M. Toscano, "Antioxidant properties of several coumarin-chalcone hybrids from theoretical insights," Royal Society of Chemistry Advances, vol. 5, no. 1, pp. 565-575, 2015.

[48] G. Mazzone, N. Russo, and M. Toscano, "Antioxidant properties comparative study of natural hydroxycinnamic acids and structurally modified derivatives: computational insights," Computational and Theoretical Chemistry, vol. 1077, pp. 39-47, 2016. 

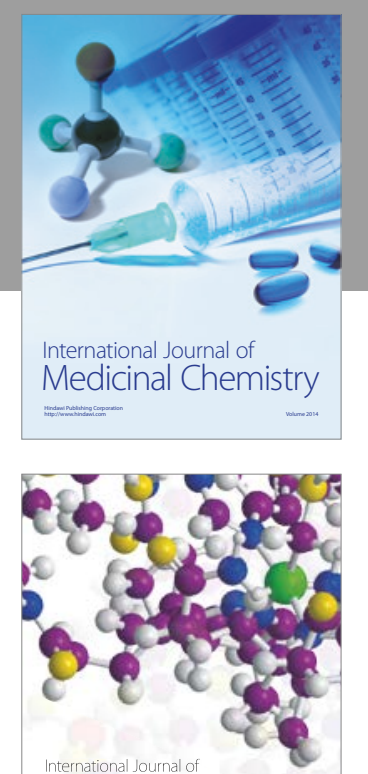

Carbohydrate Chemistry

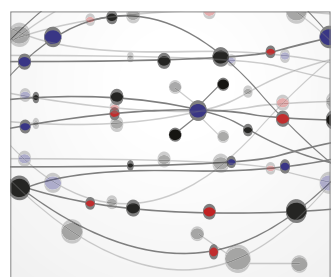

The Scientific World Journal
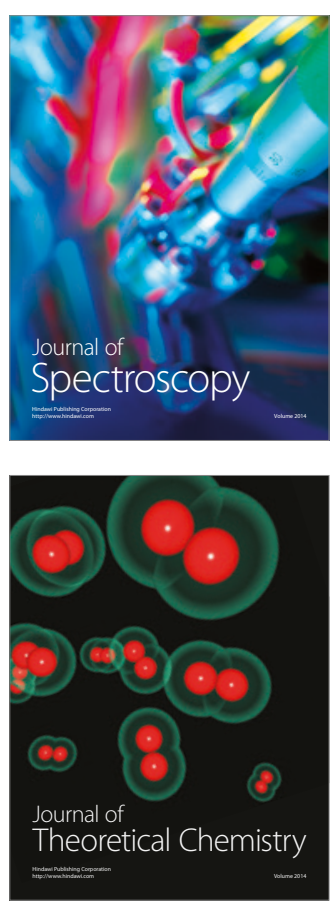
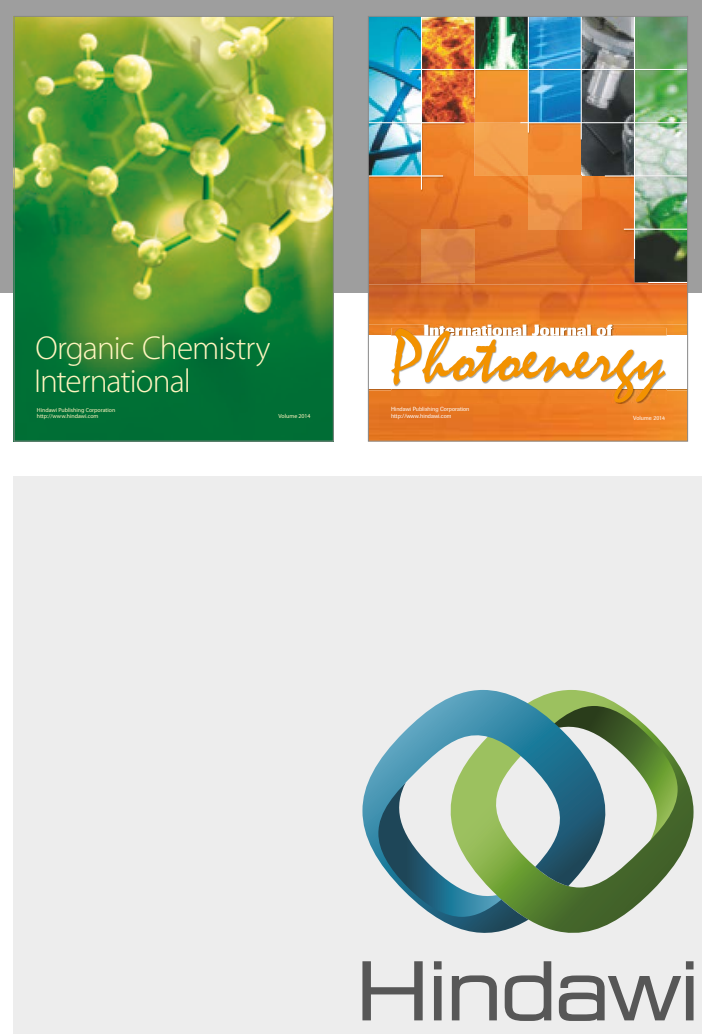

Submit your manuscripts at

https://www.hindawi.com

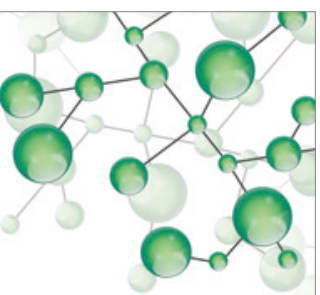

International Journal of

Inorganic Chemistry

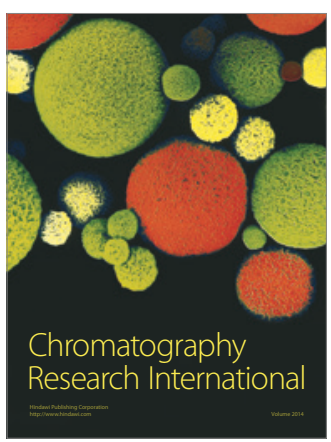

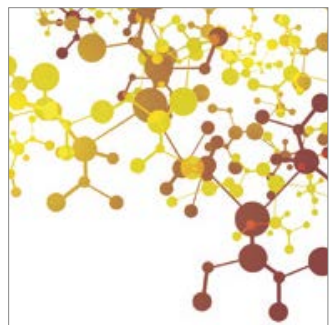

Applied Chemistry
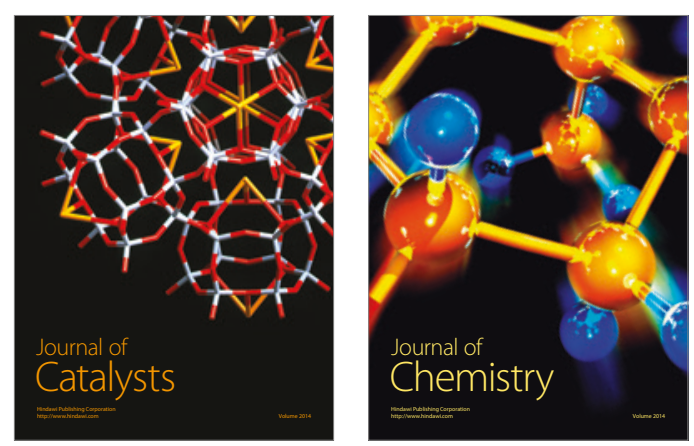
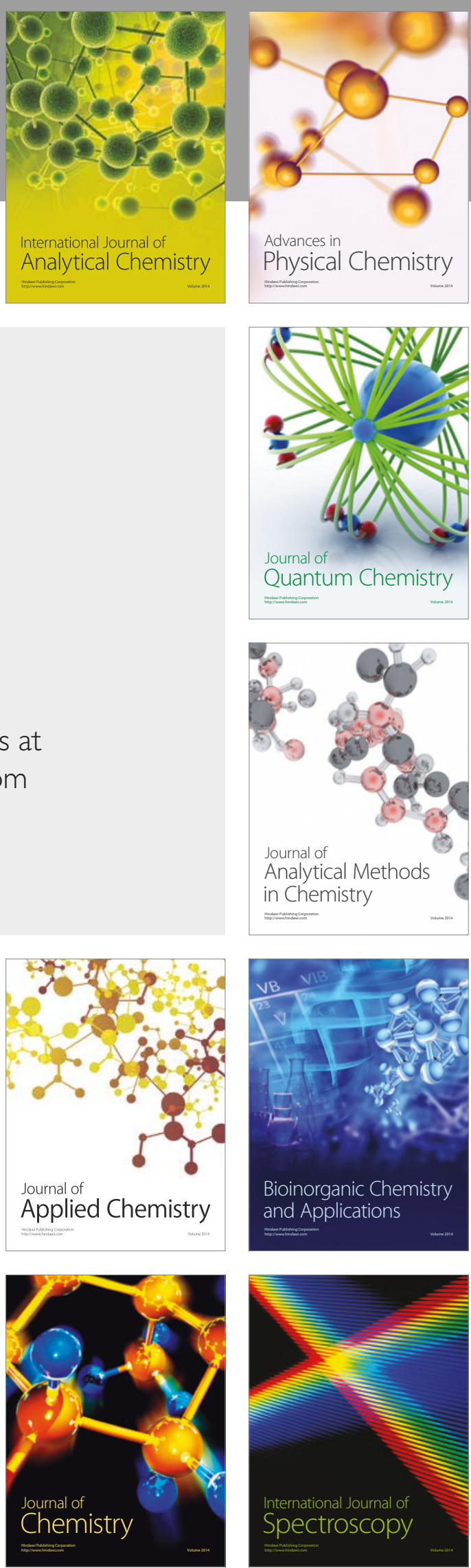